\title{
MULTI-CRITERIA DECISION TECHNIQUES IN CIVIL ENGINEERING EDUCATION. COMPARATIVE STUDY APPLIED TO THE SUSTAINABILITY OF STRUCTURES
}

\author{
Víctor Yepes ${ }^{1}$, Antonio J. Sánchez-Garrido², Ignacio J. Navarro ${ }^{2}$ \\ ${ }^{1}$ Institute of Concrete Science and Technology (ICITECH), Universitat Politècnica de \\ València (SPAIN) \\ ${ }^{2}$ Dept. of Construction Engineering, Universitat Politècnica de València (SPAIN)
}

\begin{abstract}
Traditionally, technical degrees have focused on promoting the functionality and durability of designs, orienting the capacities of their students towards the optimization of economic aspects. The challenges that have recently emerged regarding the future of the construction sector and new cities require a paradigm shift in the conventional teaching of civil engineering and architecture. New training trends have been detected in higher education programs through the introduction of new concepts, such as sustainable design. According to UNESCO, "Education for Sustainable Development promotes competencies like critical thinking, and making decisions in a collaborative way". In the postgraduate course "Models of prediction and optimization of concrete structures", taught in the Master of Concrete Engineering at the Polytechnic University of Valencia, students are instructed in research methodologies that allow the evaluation of sustainability through different multi-criteria decision techniques in the selection of the best structural typology considering economic, environmental and social aspects. In this paper, a comparative study is made and the application of the different tools taught in the course for the decision making with multiple criteria, namely SAW, COPRAS, TOPSIS, VIKOR, ELECTRE, MIVES as well as AHP for the weightings. The assess offers a transversal vision, with the characteristics, strengths and weaknesses of these multi-criteria techniques that are commonly used in the field of sustainability, applied in this case between three design alternatives for the structure of a single-family home.
\end{abstract}

Keywords: Research Methodologies, Postgraduate education, Multi-criteria decision-making, Sustainable thinking, Structural design, Residential building.

\section{INTRODUCTION}

According to UNESCO, "Education for Sustainable Development allows every human being to acquire the knowledge, skills, attitudes and values necessary to shape a sustainable future. Education for Sustainable Development requires participatory teaching and learning methods that empower learners to take action for sustainable development. Education for Sustainable Development promotes competencies like critical thinking, [...] and making decisions in a collaborative way. Education for Sustainable Development [1] requires far-reaching changes in the way education is often practiced today". In terms of sustainable design, sustainability implies ensuring that present needs are met without compromising the capability of future generations to meet their own needs. Therefore, it is of utmost importance when it comes to constructing buildings or infrastructure [2], as these are products designed to serve a large population group over a long intergenerational period. That is why engineering education must gradually provide students with the necessary tools to evaluate the environment and society together with the traditional economic dimension in their designs, thus combining the three pillars of sustainability.

Currently, there has been a transition to include sustainable design concepts [3] in the curricula of civil engineering universities. Sustainable design problems require engineers to adopt a transversal thinking to find the solution that best suits the three pillars on which sustainability is based: the economy, the environment and society [4]. Generally, the resolution of these problems consists of four phases. First, the problem to be evaluated will be precisely defined, as well as the criteria to be taken into account. Then, the particular weights of each criterion will be determined. Then, the alternatives are evaluated against each criterion individually, and finally, the results are aggregated taking into account the weight defined for each criterion. The decision is almost never simple, since the criteria that condition the decision are usually in conflict: economy, time, aesthetics, environment, society, durability, etc. 
Tools are needed to evaluate this decision process. In recent years, researchers have examined different methodologies for multi-criteria decision-making (MCDM) to assess the sustainability in construction [5] and infrastructures design [6, 7]. MCDM methods have been applied for the assessment of bridges [8,9], buildings [10,11], structural elements [12, 13] and facilities [14], among others. In the postgraduate course "Prediction and optimization models of concrete structures", taught in the Master of Concrete Engineering at the Polytechnic University of Valencia, students learn the different techniques of MCDM, even using them to obtain objective weights of criteria that can be subjective, or for the selection of the best option within a Pareto limit after a multi-objective optimization [15]. This paper aims to make a comparative study of several multi-attribute decision methods, in environments with uncertainty, applied to three different constructive alternatives based on modern constructive methods (MMC). The objective is to define the sustainable alternative that best meets the different perspectives, whatever the interests of the DMs. For this purpose, a set of criteria was used to reach all the building's sustainability perspectives, considering its entire life cycle. Thus, a comprehensive sustainability assessment can be carried out.

\section{METHODOLOGY}

The process of making decisions according to different objectives is usually supported by the use of different methods and tools MCDM designed for this purpose. The multi-criteria decision making processes can be classified into multi-attribute decision making (MADM), and multi-objective decision making (MODM). More specifically, MADMs allow the solution of discrete problems when the alternatives are predetermined and the experts evaluate each criterion beforehand, indicating the importance of each one. In this case, the DMs act at the beginning of the process, either by giving weights to the different existing criteria for the evaluation of each of the solutions, or by evaluating these solutions according to subjective criteria. Finally, a prioritization of the alternatives studied is obtained.

\subsection{Multi-Criteria Assessment Techniques}

There are a wide variety of methods and tools available to solve MADM problems, used to decide on a finite number of solutions. Below are the most commonly used methods for decision making according to the most common grouping used [16,17].

- Direct scoring methods are the most straightforward, being based on the evaluation of the different alternatives through basic arithmetic operations. SAW and COPRAS assess the alternatives by aggregating the standardized value of each criterion by its corresponding weight.

- Distance-based methods calculate the distance between each alternative and a specific point. CP, TOPSIS and VIKOR are based on obtaining the alternative that satisfies a set of goals, that is, the point is not the optimal one, but the one that fulfills a series of conditions, differing in the normalization of the criteria.

- Paired comparison methods, including AHP, ANP and MACBETH, are worthwhile for obtaining the weights of the different criteria and for evaluating the subjective criteria by comparing the alternatives with each other.

- Outranking methods establish a relationship of preference between a set of solutions where each one of them shows a degree of dominance over the others with respect to a criterion. These methods are capable of dealing with incomplete and diffuse information, and allow classifying the alternatives according to the preference relationship between them. Within this group are PROMETHEE and ELECTRE.

- Utility/value methods define functions that determine the degree of satisfaction of an alternative with respect to a criterion. These functions convert the evaluations of the alternatives into a degree of satisfaction for each criterion. These functions have different formats according to the relationship between the valuation and the degree of satisfaction. MAUT, MAVT and MIVES are examples of the above.

In this paper we will focus on comparing five methods: SAW, COPRAS, TOPSIS, VIKOR, ELECTRE and MIVES. The main reason is that all of them share the same decision process illustrated in Figure 1 , and whose evaluation procedure consists of: normalization and weighting, index calculation and ranking construction. In addition, the input data are the same and do not need extra information from the DM, apart from the decision matrix and the weighting vector. 


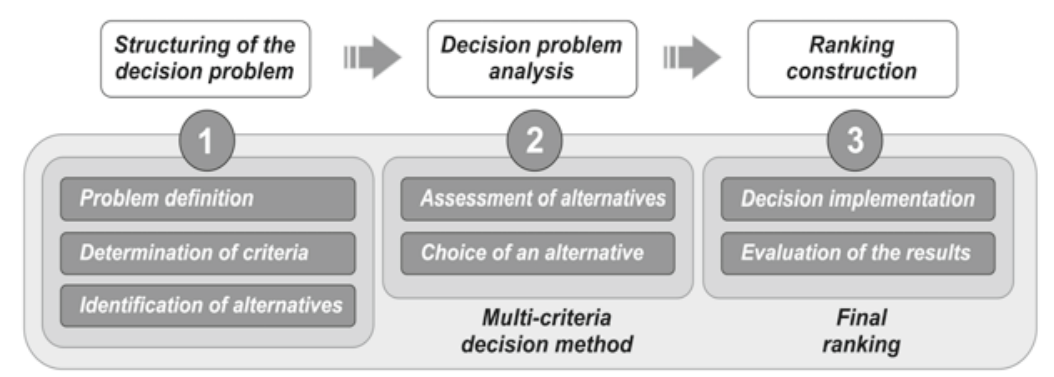

Figure 1. Elements involved in a decision process

\subsubsection{SAW}

The Simple additive weighting (SAW) is the most widely used technique [ ] whose popularity is based on its ease of use. This method consists of obtaining the sum for each alternative $\left(S_{j}\right)$ of the product of each standardized criterion $\left(r_{i j}{ }^{\prime}\right)$ and its relative weight $\left(w_{i}\right)$.

$$
S_{j}=\sum_{i=1}^{m} w_{i} \cdot r_{i j}{ }^{\prime}=\sum_{i=1}^{m} v_{i j}
$$

When the sum of all the alternatives is obtained, they are compared and ordered in ascending order. The most valuable alternative will be the best. The attribution of the relative weight of each criterion is assigned by the experts directly. The standardization of a criterion of an alternative $\left(r_{i j}{ }^{\prime}\right)$ is done by the quotient of the value of the criterion of that alternative $\left(r_{i j}\right)$ between the maximum value of that criterion for all the alternatives $\left(\max _{j} r_{i j}\right)$ :

$$
r_{i j}{ }^{\prime}=r_{i j} / \max _{j} r_{i j}
$$

To normalize the criteria to be used for minimization, a transformation from minimization to maximization is made, whereby the normalization of one criterion of an alternative $\left(r_{i j}{ }^{\prime}\right)$ is made by the ratio of the minimum value of that criterion for all the alternatives $\left(\min _{j} r_{i j}\right)$ between the value of the criterion of that alternative $\left(r_{i j}\right)$ :

$$
r_{i j}{ }^{\prime}=\min _{j} r_{i j} / r_{i j}
$$

\subsubsection{COPRAS}

The Complex Proportional Assessment (COPRAS) is an evolution of the SAW method. It expresses the criteria values in intervals based on real conditions and enables the evaluation of the criteria uncertainty value. The evaluation of the criteria to be maximized and minimized is done separately, the sum for each alternative $\left(Z_{j}\right)$ being the value obtained in the following expression:

$$
Z_{j}=S_{+j}+\frac{S_{-m i n} \cdot \sum_{j=1}^{n} S_{-j}}{S_{-j} \cdot \sum_{j=1}^{n} \frac{S_{-m i n}}{S_{-j}}}
$$

The first term $S_{+j}$ of the expression is the component of the criteria to be maximized, which is obtained just like the SAW method, therefore if there are no criteria to be minimized, the SAW and COPRAS methods turn out to be the same.

$$
Z_{+}=S_{+j}=\sum_{i=1}^{m} w_{+i} \cdot r_{+i j}{ }^{\prime}
$$

The second term of the expression is the component of the criteria to minimize, where $S_{-j}$, is the same expression as $S_{+j}$ but applied to the criteria to minimize, being $S$-min, the minimum value of $S_{-j}$ of all the alternatives. Since $S_{\text {-min }}$ is a constant, the expression can be simplified by being cancelled because it is in the numerator and denominator.

$$
Z_{-}=\frac{\sum_{j=1}^{n} S_{-j}}{S_{-j} \cdot \sum_{j=1}^{n} \frac{1}{S_{-j}}}
$$

The COPRAS method, with these expressions, manages to obtain a value for each alternative $\left(Z_{j}\right)$ that is directly proportional to the positive or maximization component $\left(Z_{+}\right)$and inversely proportional to the negative or minimization component (Z-). 


\subsubsection{TOPSIS}

The Technique for Order of Preference by Similarity to Ideal Solution (TOPSIS) is a method to find the solution closest to the positive ideal solution (PIS) and farthest from the negative ideal solution (NIS). The PIS of each criterion will be the maximum if you want to maximize the criterion and the minimum if you want to minimize the criterion, and the NIS will be the minimum if you want to maximize the criterion and the maximum if you want to minimize the criterion. Firstly, each score $\left(r_{i j}\right)$ of the criteria of each alternative is normalized $\left(r_{i j}{ }^{\prime}\right)$ in the following way:

$$
r_{i j}^{\prime}=r_{i j} / \sqrt{\sum_{j=1}^{m} r_{i j}^{2}}
$$

Each of these values is multiplied by the corresponding relative weight $\left(w_{i}\right)$ so that the normalized value $\left(v_{i j}\right)$ is obtained multiplied by the relative weight. Then, the Euclidean distance (through the metric $\left.L_{2}\right)$ to the PIS $\left(D_{j}^{*}\right)$ and NIS $\left(D_{j-}\right)$ of each alternative is obtained so that:

$$
\begin{gathered}
D_{j}^{*}=\sqrt{\sum_{i=1}^{n}\left(v_{i j}-v_{i}^{*}\right)^{2}} \\
D_{j}^{-}=\sqrt{\sum_{i=1}^{n}\left(v_{i j}-v_{i}^{-}\right)^{2}}
\end{gathered}
$$

Finally, the relative distance to the ideal of each alternative $j$ is calculated and classified, choosing the alternative that has the least distance to SIP and the furthest from NIS, i.e., the alternative with the highest score will be better.

$$
C_{j}^{*}=D_{j}^{-} / D_{j}^{*}+D_{j}^{-}
$$

\subsubsection{VIKOR}

The multi-criteria optimization and compromise solution (VIKOR in Serbian) ranks and determines a compromise solution from a finite set of viable alternatives that have conflicting criteria measured with different units. Once the decision matrix that makes up the problem has been composed, the positive ideal solution PIS ( $\left.\mathrm{A}^{*}\right)$ and the negative ideal solution NIS $\left(\mathrm{A}^{-}\right)$of the $n$ criteria are identified for each alternative, and each score is then normalized:

$$
r_{i j}{ }^{\prime}=\left(r_{i}^{*}-r_{i j}\right) /\left(r_{i}^{*}-r_{i}^{-}\right)
$$

The weights $\left(w_{i}\right)$ for each criterion are then assigned. The VIKOR method contemplates the Manhattan $\left(L_{1}\right)$ and Chebyshev $\left(L_{\infty}\right)$ distance, according to the $S$ and $R$ indices, respectively. $S$ is the aggregation of the values of the alternatives according to the $L_{1}$ metric, which considers the group utility of the criteria. $R$ uses the metric $L_{\infty}$ which takes into account the individual minimum of each criterion to find the maximum distance from the alternative to the ideal solution, i.e. the worst possible case:

$$
\begin{aligned}
S_{j} & =\sum_{i=1}^{m} w_{i}\left(r_{i}^{*}-r_{i j}\right) /\left(r_{i}^{*}-r_{i}^{-}\right) \\
R_{j} & =\max \left[w_{i}\left(r_{i}^{*}-r_{i j}\right) /\left(r_{i}^{*}-r_{i}^{-}\right)\right]
\end{aligned}
$$

The final ranking is obtained by determining the relative distance of each $Q_{j}$ alternative according to the equation:

$$
Q_{j}=v \cdot \frac{\left(S_{j}-S^{*}\right)}{S^{-}-S^{*}}+(1-v) \cdot \frac{\left(R_{j}-R^{*}\right)}{R^{-}-R^{*}}
$$

where $S^{*}=\min S_{j}, S^{-}=\max S_{j}, R^{*}=\min R_{j}, R^{-}=\max R_{j}$, weighted through the variable $v \in[0,1]$ that determines the importance of each distance, balancing the indexes $S$ and $R$. To make a brief sensitivity study, this work considers that $v$ will take the values of $0,0.5$ and 1 .

\subsubsection{ELECTRE}

The Elimination et choix tradusiant la realité (ELECTRE) is supported by a concordance $(c)$ and discordance $(d)$ index. In a pair of alternatives $\left(A_{j}\right.$ and $\left.A_{k}\right)$ the concordance index $\left(c_{j k}\right)$ is the sum of the weights of those criteria whose value in alternative $j$ is greater than in alternative $k$.

$$
c_{j k}=\sum_{i=1}^{n} w_{i} \text { con } j, k=1, \ldots, n y \neq k
$$


where, $w_{i}$ are the weights of criterion $i$. Therefore the concordance value will be a value between 0 and 1. In the same pair of alternatives $\left(A_{j}\right.$ and $\left.A_{k}\right)$, the index of discordance $\left(d_{j k}\right)$ will be 0 if alternative $j$ is greater than alternative $k$ in all criteria, and in all other cases it will be equal to:

$$
d_{j k}=\max _{i=1, \ldots, m}\left[r_{i k}^{\prime}-r_{i j}^{\prime}\right] \text { con } j, k=1, \ldots, n y \neq k
$$

where $r_{i k}^{\prime}$ and $r_{i j}^{\prime}$ are the normalized values between 0 and 10 of the $r_{i k}$ and $r_{i j}$ scores.

Obtaining the concordance and discordance indexes for each pair of alternatives we obtain the concordance and discordance matrices. The threshold of agreement $c^{*}$ is defined as the next value higher or equal to the average in the numbers of the agreement matrix, and the threshold of discordance $d^{*}$ is defined as the next value lower or equal to the average in the discordance matrix. An alternative $A_{j}$ exceeds $A_{k}$ si:

$$
c_{j k}>c^{*} y \quad d_{j k}<d^{*}
$$

This provides us with a partial ranking (between pairs of alternatives) where we see that if the alternative $A_{j}$ dominates the alternative $A_{k}$ or not (in case of not fulfilling 1 of the two previous conditions). Performing this process by rows we obtain the number of dominances of one alternative with respect to another in rows, and doing the same by columns the number of dominances of one alternative with respect to another in columns. Finally, the number of dominances in the rows and columns of each alternative is subtracted to obtain the difference in dominance. The alternative with the largest dominance difference will be the most appropriate.

\subsubsection{MIVES}

MIVES method (in Spanish "Integrated Value Model for Sustainable Assessments") is based on utility or value functions that determine the degree of satisfaction of an alternative with respect to a criterion. The value function converts indicators with physical units into common units (values). For an indicator, a given function is being defined, the mathematical expression of which depends on the parameters that have been adopted. Equation (1) is the standard formula of the value function that will evaluate the satisfaction with respect to the indicator.

$$
V_{i}=B \cdot\left[1-e^{-k_{i}}\left(\left|x-x_{\min }\right| / c_{i}\right)^{P_{i}}\right]
$$

The variable $B$, as defined in Equation (2), preserves the range of the function $\{0-1\}$ according to five parameters (see Table 1). $\mathrm{Pi}(0<P<\infty)$ is a factor that defines the shape of the curve; $C_{i}$ establishes $\mathrm{n}$ curves with $P_{i}>1$, the value of the abscissa for the inflection point; $K_{i}(0<K<1)$ is the ordinate for the inflection point; $X_{\min }$ is the value in abscissas whose response is equal to zero in the case of increasing functions (for decreasing functions the minimum value is $X_{\max }$ ); and, finally, $X$ is the abscissa of the evaluated indicator that generates a $V_{i}$ value (variable for each alternative).

$$
B=1 /\left[1-e^{-k_{i}}\left(\left|x_{\max }-x_{\min }\right| / c_{i}\right)^{P_{i}}\right]
$$

This function is designed to convert the quantification or qualification of an attribute into a dimensionless variable between 0 and 1 . It is an essential element to assign a correct form to the value function and, above all, to properly determine the points of maximum and minimum satisfaction. From a conceptual point of view, the approach is to transform subjectivity into objectivity.

Table 1. Parameters of the value function

\begin{tabular}{ccc}
\hline Function & $\boldsymbol{P}_{\boldsymbol{i}}$ & $\mathrm{K}_{\boldsymbol{i}}$ \\
\hline Concave / Essential & $<0.75$ & $>0.9$ \\
Convex / Normative & $>2$ & $<0.1$ \\
Linear / Proportionate & 1 & 0 \\
S-Shaped (soft) & $2<\mathrm{P}_{\mathrm{i}}<4$ & $0.1<\mathrm{K}_{\mathrm{i}}<0.2$ \\
S-Shaped (steep) & $4<\mathrm{P}_{\mathrm{i}}<10$ & $0.1<\mathrm{K}_{\mathrm{i}}<0.2$ \\
\hline
\end{tabular}




\subsection{Criteria and subjective weighting}

In order to minimize the subjectivity of individual decision-makers caused by the dispersion among the large number of defined indicators, the expert group has focused on the evaluation of 9 criteria distributed among the 3 pillars of sustainability, namely, the economy, the environment and society.

To evaluate the economic dimension, cost has been considered as the only unit of impact. However, the economic resources have been quantified in indicators according to each phase of the life cycle, which facilitates the introduction of data and the subsequent analysis of the results. The construction costs in the three alternatives for each phase of the building life cycle (design, construction, service and demolition) were calculated using information provided by national databases specific (Construction Price Generator, BEDEC PR/PCT ITEC, among others).

In the environmental field, we have integrated the concept of recycling into the criteria. When a material has already reached the end of its useful life in a building, it can be reused as a resource in other applications. This process reduces the impact on the environment (less natural resources are required) and the use of energy (natural resource extraction is saved). The estimation of the environmental impacts of the life cycle follows the methodology of ReCiPe. The method provides a synthesis of 18 mid-point indicators, which are more difficult to interpret, into the three end-point indicators used in this study, namely, damage to human health, depletion of natural resources, and damage to ecosystems. In addition, these three categories of endpoints are common to most "endpoint methodologies" such as the Eco-Indicator 99 or Impact 2002+. ReCiPe, in particular, is one of the most accepted that have been commonly used in the current literature [18].

All the proposed social criteria have been chosen specifically to characterize the social impacts on five stakeholders, namely the local community, consumers, value chain actors, workers and society. These stakeholders are based on a hotspot analysis according to the "Guidelines for Social Life Cycle Assessment of Products" [19], taking into consideration the social context of the site and of the production centers involved in the system of the product under consideration.

In this study the criteria were chosen through seminars of six experts, which according to some authors $[20,21]$, is the number needed to stabilize the AHP matrix with credible and reliable results. The participants are active professionals with at least 5 years of experience in the field of architecture, civil engineering or construction. Weighting is a key step in the decision-making process, which in this case has been done by comparing the different criteria in pairs using the mathematical theory called Hierarchical Analytical Process (AHP) [22] according to a scale proposed by Saaty (1980). In order to do so, the decision-maker must indicate which of the two criteria compared is more important and how much more important it is by means of linguistic responses associated with numerical values. A matrix of comparisons is then formed, from which the weights of the criteria are obtained by means of estimation methods such as the main autovector. This matrix complies with the properties of reciprocity (if $a_{i j}=x$, then $a_{j i}=1 / x$ ); homogeneity (if $i$ and $j$ are equally important, $a_{i j}=a_{j i}=1$, and furthermore, $a_{i i}=1$ for all $i$ ); and consistency. Consistency is obtained by means of the Consistency Index:

$$
C I=\lambda_{\max }-n / n-1
$$

where $\lambda_{\max }$ is the maximum eigenvalue and $n$ the dimension of the decision matrix. A null value for this index corresponds to a perfect consistency.

Figure 2 summarizes the decision criteria assumed here, as well as the local and global weights representing the relative significance of the criteria among themselves and with respect to the three dimensions of sustainability.

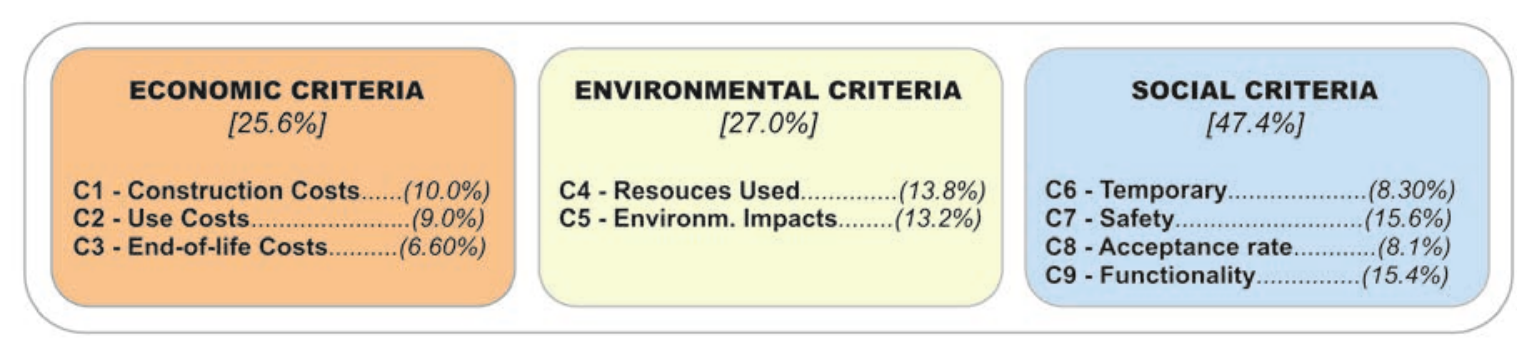

Figure 2. Sustainability criteria and weights (global and local) 


\section{CASE STUDY}

\subsection{Building description}

This paper aims to analyze sustainability in residential building, comparing different options for the design of the structure and the enveloping walls from a life cycle perspective. The study focuses on a single-family townhouse in contact with others, side-by-side. This typology is widely used in areas of residential single-family building development whose morphology is characterized by the correlation between plots where the street has been the structuring element. It has spread globally, especially in expansion areas of big cities expansion, because it allows an average economic cost, affordable for a large number of people who prefer to live in single-family homes rather than in collective ones. Its elongated and narrow geometry has been the result of the maximum adjustment of the parameters of building density, surface area, occupation and urban planning.

The plot, which is located in Jaén (Spain), has a rectangular shape of $6.20 \mathrm{~m} \times 20.00 \mathrm{~m}$ and access from street level according to Fig. 3. The two-storey house involves of a semi-basement level with use of a garage; level 0 elevated above the sidewalk, with living room, kitchen and toilet; level 1 with 3 bedrooms, bathroom and toilet; level 2 with solarium and swimming pool and a small roof for the tower. The geotechnical report reveals that the soil is very unfavorable, with a low load capacity due to the presence of marl and expansive clay. The soil is also very aggressive, due to its sulphate content.
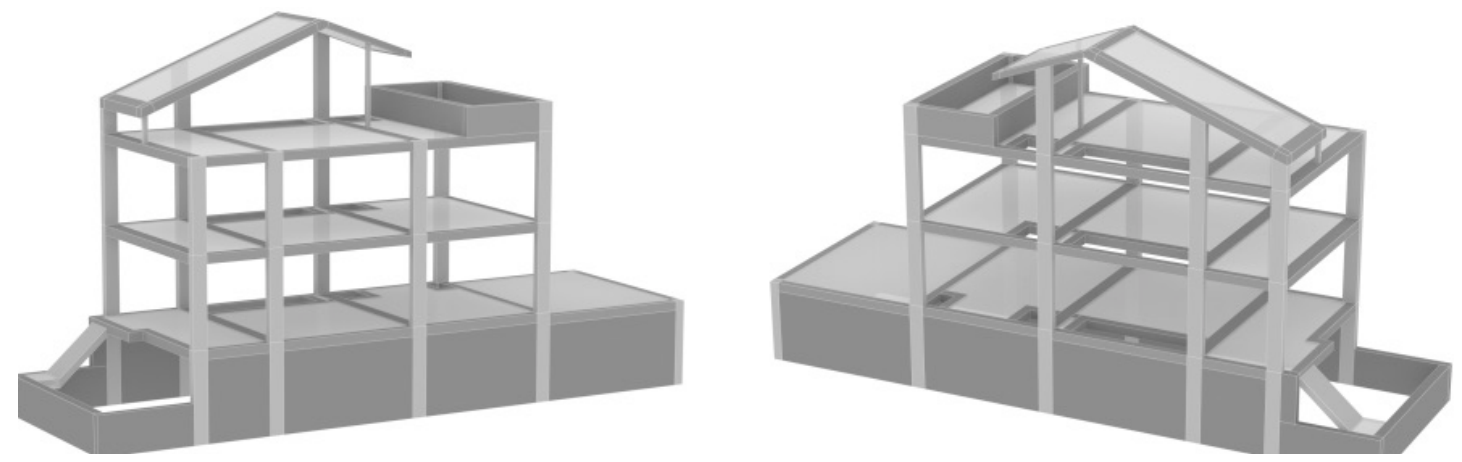

Figure 3. Model of the structure for the single-family house

\subsection{Features of the alternatives}

In order to decide the sustainable alternative that best represents the different interests of DMs, it is proposed to compare a traditional reference solution with two construction options based on modern methods of construction (MMC). Table 2 describes these construction options for each of the components studied.

Table 2. Characterization of the alternatives

\begin{tabular}{|c|c|c|}
\hline Alternative & Components & Description \\
\hline \multirow{5}{*}{$\begin{array}{c}1 \\
\text { "Reference" }\end{array}$} & Foundation & $\begin{array}{l}\varnothing 35 \mathrm{~cm} \text { CPI-7 piles with } \mathrm{HA}-35 / \mathrm{F} / 12 / \mathrm{lla}+\mathrm{Qc} \text { up to } 8.80 \mathrm{~m} \text { deep and foundation } \\
\text { beams with } \mathrm{HA}-30 / \mathrm{B} / 20 / / \mathrm{la}+\mathrm{Qb}\end{array}$ \\
\hline & Floor slabs & $\begin{array}{l}\text { Reinforced concrete slab with HA-25/B/20/lla (floor type } 24 \mathrm{~cm} ; 26 \mathrm{~cm} \text { in solarium) } \\
\text { and HA-30/B/20//V in the pool. }\end{array}$ \\
\hline & Sloping floor slab & Reinforced concrete slab HA-25/B/20/lla $(22 \mathrm{~cm})$ and $10 \mathrm{~cm}$ PUR. \\
\hline & Supports & $\begin{array}{l}\text { Concrete columns and metal profiles (only in props of the roof). Reinforced } \\
\text { concrete basement perimeter wall }(25 \mathrm{~cm}) \text {. }\end{array}$ \\
\hline & Building enclosure & Brick outer wall $(11.5 \mathrm{~cm})$; with $9 \mathrm{~cm}$ MW and interior brick partition wall $(7 \mathrm{~cm})$. \\
\hline \multirow{5}{*}{$\begin{array}{c}2 \\
\text { "Ytong" } 2\end{array}$} & Foundation & Same to alternative "A". \\
\hline & Floor slabs & $\begin{array}{l}\text { Reinforced plates (floor type } 30 \mathrm{~cm} \text { and } 12.5 \mathrm{~cm} \text { in the turret); Density } 600 \mathrm{~kg} / \mathrm{m}^{3} \text {. } \\
\text { Passable deck not ventilated, fixed floor with } 8 \mathrm{~cm} \text { XPS. Pool basin with } 30 \mathrm{~cm} \\
\text { plates (live load } 1,100 \mathrm{Kg} / \mathrm{m} 2 \text { ) and reinforced concrete block wall. }\end{array}$ \\
\hline & Sloping floor slab & Reinforced plates $(12 \mathrm{~cm}) ; 12 \mathrm{~cm}$ XPS $\left(0.032 \mathrm{~m}^{2} \mathrm{~K} / \mathrm{W}\right)$. \\
\hline & Supports & There are no columns. Reinforced concrete basement wall is maintained. \\
\hline & Building enclosure & $\begin{array}{l}\text { Structural load-bearing walls with tongue and groove aerated concrete blocks (20- } \\
30 \mathrm{~cm} \text { ) with densities }\left(400-350 \mathrm{Kg} / \mathrm{m}^{3}\right) \text {. }\end{array}$ \\
\hline
\end{tabular}




\begin{tabular}{|c|c|c|}
\hline \multirow{5}{*}{ "Elesdopa" 3} & Foundation & $\begin{array}{l}\text { Mat foundation 7/46/7 on } 1.00 \text { m deep compacted soil improvement. } \\
\text { HRA-30/B/12/lla+Qb; } 46 \text { cm interior gravel filling. }\end{array}$ \\
\hline & Floor slabs & $\begin{array}{l}\text { Sprayed reinforced concrete lightened slab HRA-25/B/12/lla (floor type 6+18+6 } \\
\mathrm{cm} ; 7+26+7 \mathrm{~cm} \text { solarium) and HRA-30/B/12/IV in pool. Passable deck not } \\
\text { ventilated, fixed flooring; } 26 \mathrm{~cm} \text { XPS. }\end{array}$ \\
\hline & Sloping floor slab & Sprayed reinforced concrete lightened slab $(5+5+5 \mathrm{~cm}) ; 5 \mathrm{~cm}$ XPS. \\
\hline & Supports & Reinforced concrete basement wall is maintained. \\
\hline & Building enclosure & $\begin{array}{l}\text { Structural walls in façade and dividing walls }(6+13+6 \mathrm{~cm}) \text {; interior air chamber } \\
\text { formed with } 13 \mathrm{~cm} \text { EPS. }\end{array}$ \\
\hline
\end{tabular}

\subsection{Results}

The summary of the results obtained with the different methods is shown in table 3 . In general, alternative 3 is the best evaluated, followed by alternative 2, except in the case of MIVES and VIKOR $(v=1)$. In no case alternative 1 , which has been used as a reference, obtains the best score.

Table 3. Comparison with the results of MADM methods

\begin{tabular}{|c|c|c|c|c|c|}
\hline $\begin{array}{l}\text { MADM } \\
\text { method }\end{array}$ & Summary score & & $\begin{array}{l}\text { Alternative } 1 \\
\text { "Reference" }\end{array}$ & $\begin{array}{c}\text { Alternative } 2 \\
\text { "Ytong" }\end{array}$ & $\begin{array}{l}\text { Alternative } 3 \\
\text { "Elesdopa" }\end{array}$ \\
\hline SAW & Final score ${ }^{1}$ & & 0.77 & 0.87 & 0.89 \\
\hline COPRAS & Final score $^{1}$ & & 0.77 & 0.86 & 0.88 \\
\hline TOPSIS & Final score $^{1}$ & & 0.43 & 0.50 & 0.62 \\
\hline \multirow{3}{*}{ VIKOR } & \multirow{3}{*}{ Score $^{2}$} & $v=0$ & 1 & 0.97 & 0 \\
\hline & & $v=0.5$ & 1 & 0.49 & 0.02 \\
\hline & & $\mathrm{v}=1$ & 1 & 0 & 0.04 \\
\hline ELECTRE & Ranking & & $3^{\mathrm{a}}$ & $2^{\mathrm{a}}$ & $1^{\mathrm{a}}$ \\
\hline \multirow{4}{*}{ MIVES } & Economic rating ${ }^{1}$ & & 0.15 & 0.16 & 0.20 \\
\hline & Environmental rating ${ }^{1}$ & & 0.04 & 0.17 & 0.11 \\
\hline & Social rating ${ }^{1}$ & & 0.25 & 0.26 & 0.26 \\
\hline & Final score ${ }^{1}$ & & 0.43 & 0.59 & 0.57 \\
\hline
\end{tabular}

${ }_{1}^{1}$ The highest score the best

${ }^{2}$ The shorter the distance, the better.

The direct scoring methods (SAW and COPRAS) offer practically the same final score. This is because the COPRAS method is an evolution of the SAW method to assess negative criteria or criteria that are to be minimized. In any case, the SAW method already solves it with different standardization techniques. These methods are the simplest, very suitable for problems in which all variables are quantitative. However, in the case of assessing the sustainability of building structures there are both quantitative and qualitative or semantic variables, so they are not the most appropriate but serve as a first approach to the problem.

The distance-based methods (TOPSIS and VIKOR), although they have a common basis, differ in the way the final score is given. In the case of TOPSIS, although the distances to the PIS and NIS are calculated, normalization is made at the end. This is why a higher score is obtained for the best alternative. On the other hand, VIKOR is different, obtaining as a result the distance of each alternative to the ideal. With the VIKOR method we have taken advantage of the opportunity to carry out a sensitivity study by modifying the variable $v$. The results show that as the value of $v$ increases, alternative 3 loses importance in favor of alternative 2 . This is due to the fact that the distance from Manhattan $\left(S_{j}\right)$ benefits alternative $2\left(S_{1}=0.77 ; S_{2}=0.30 ; S_{3}=0.32\right)$, to the extent that for $v=1$ the latter becomes the preferred one. The TOPSIS and VIKOR methods are very useful when the optimal ideal solution is known and the non-optimal ideal solution is known. Therefore, in addition to their use in 
multi-attribute decision making, they can be used for the selection of an alternative within a Pareto limit for a multi-objective optimization problem.

Among the methods of outranking, ELECTRE offers both a global ranking of the alternatives, and a comparison between them. In the global ranking of the alternatives it is observed that alternative 3 is in first position and alternative 2 in second position, but if we observe the comparisons between these two it is deduced that none is strictly superior to the other. The ELECTRE and PROMETHEE methods are very suitable for the classification of alternatives according to degree of dominance by pairs, being very useful for discrete problems of multi-attribute decision making.

Finally, the MIVES method offers different results to the tendency of the ranking until now, obtaining the alternative 2 the best sustainability index (0.59), although followed closely by the alternative 3 (0.57). This disparity with the rest of MADM methods is explained by the subjective load introduced by each $\mathrm{DM}_{\mathrm{k}}$. The results are sensitive to the selection of the value function that best fits the criteria according to the judgment of the DMs, as well as to the ranges between the $P_{i}$ and $K_{i}$ parameters. An advantage of MIVES is that it allows to prioritize the criteria, which is very useful to include common criteria. It can be observed that although alternative 3 has the best score in the economic $(0.20)$ and social $(0.26)$ dimensions, the global evaluation is favorable to alternative 2 since it presents the most balanced indexes.

\section{CONCLUSIONS}

In this document a study of the decision-making process has been carried out to evaluate the sustainability of the structure of a row house, applying the most important methods of MADM. This learning object belongs to the postgraduate course "Prediction and optimization models of concrete structures" integrated in the curriculum of the Master of Concrete Engineering of the UPV. In these courses it is taught how to apply MCDM techniques in the selection of the best structural typology for the resolution of complex engineering problems. The assessment of the sustainability of structures relies on numerous variables that can make the solution opt for one or another alternative: the criteria considered, the weights assigned and the multi-attribute decision methods employed. All this makes the MCDM process a very complicated process that involves a great deal of uncertainty, which can be taken into account by means of support tools for the decision-making process, such as fuzzy theory or neutrosophic logic, although at the cost of increasing complexity. The process of decision making by multiple attributes always has the same steps, although the way to carry them out is what differentiates one methodology from another. All of them have their advantages and disadvantages, although their choice or preference remains subjective. However, these methods can be modified and adapted to fit the objective of the decision maker. From the analysis of the selected criteria, with any of the methods, it is concluded that only the concurrent consideration of the three pillars of sustainability in a building structure will lead to appropriate sustainable designs.

\section{ACKNOWLEDGEMENTS}

The authors acknowledge the financial support of the Spanish Ministry of Economy and Competitiveness, which was co-financed with FEDER funds (Project: BIA2017-85098-R).

\section{REFERENCES}

[1] L. Scherak, M. Rieckmann, "Developing ESD Competences in Higher Education InstitutionsStaff Training at the University of Vechta", Sustainability, vol. 12 no. 24, p. 10336, 2020.

[2] V. Yepes, E. Pellicer, J.A. Ortega, "Designing a benchmark indicator for managerial competences in construction at the graduate level", Journal of Professional Issues in Engineering Education and Practice, vol. 138, no. 1, pp. 48-54, 2012.

[3] B. Colin, S. Remmer, "Sensemaking of a sustainability transition by higher education institution leaders", Journal of Cleaner Production, vol. 256, p. 120299, 2020.

[4] I.J. Navarro, A.J. Sánchez-Garrido, V. Yepes, "Evaluation of sustainability-oriented transversal competencies in engineering postgraduate studies", $13^{\text {th }}$ annual International Conference of Education, Research and Innovation ICERI, 9-10 nov 2020. 
[5] D. Jato-Espino, E. Castillo-Lopez, J. Rodriguez-Hernandez, J., J. C. Canteras-Jordana. "A review of application of multi-criteria decision making methods in construction". Automation in Construction, vol. 45, pp. 151-162, 2014.

[6] I.J. Navarro, V. Yepes and J.V. Martí, "A review of multi-criteria assessment techniques applied to sustainable infrastructures design", Advances in Civil Engineering, vol. 2019, p. 6134803, 2019.

[7] H. Gervasio and L. Simões da Silva, "A probabilistic decision-making approach for the sustainable assessment of infrastructures", Expert Systems with Applications, vol. 39, no. 8, pp. 7121-7131, 2012.

[8] T. García-Segura, V. Yepes, D.M. Frangopol, "Multi-Objective Design of Post-Tensioned Concrete Road Bridges Using Artificial Neural Networks", Structural and Multidisciplinary Optimization, vol. 56, no. 1, pp. 139-150, 2017.

[9] V. Penadés-Plà, J.V. Martí, T. García-Segura, V. Yepes, "Life-cycle assessment: A comparison between two optimal post-tensioned concrete box-girder road bridges", Sustainability, vol. 9, no. 10, p. 1864, 2017.

[10] A.J. Sánchez-Garrido and V. Yepes, "Multi-criteria assessment of alternative sustainable structures for a self-promoted, single-family home", Journal of Cleaner Production, vol. 258, p. 120556, 2020.

[11] A. Hosseini, A. De la Fuente, O. Pons, "Multi-criteria decision-making method for assessing the sustainability of post-disaster temporary housing units technologies: A case study in Bam, 2003". Sustainable Cities and Society, vol. 20, pp. 38-51, 2016.

[12] I. Payá-Zaforteza, V. Yepes, F. González-Vidosa, A. Hospitaler, "On the Weibull cost estimation of building frames designed by simulated annealing", Meccanica, vol. 45, no. 5, pp. 693-704, 2010.

[13] F. Molina-Moreno, T. García-Segura, J.V. Martí, V. Yepes, "Optimization of Buttressed EarthRetaining Walls using Hybrid Harmony Search Algorithms", Engineering Structures, vol. 134, pp. 205-216, 2017.

[14] I. Aschilean, I. Giurca, "Choosing a water distribution pipe rehabilitation solution using the analytical network process method", Water vol. 10, no. 4, p. 484, 2018.

[15] T. García-Segura, V. Penadés-Plà and V. Yepes, "Sustainable bridge design by metamodelassisted multi-objective optimization and decision-making under uncertainty", Journal of Cleaner Production, vol. 202, pp. 904-915, 2018.

[16] S. Hajkowicz, K. Collins, "A review of multiple criteria analysis for water resource planning and management". Water Resources Management, vol. 21, pp. 1553-1566, 2007.

[17] M. De Brito, M. Evers, "Multi-criteria decision-making for flood risk management: A survey of the current state of the art". Natural Hazards and Earth System Sciences, vol. 16, pp. 1019-1033, 2016.

[18] A.J. Sánchez-Garrido, I.J. Navarro, V. Yepes, "Multi-criteria decision making applied to engineering education. Economic-environmental sustainability in the structure of single-family homes", $13^{\text {th }}$ annual International Conference of Education, Research and Innovation ICERI, 9-10 nov 2020.

[19] United Nations Environment Programme and SETAC, "Methodological Sheets for the Subcategories of Social Life Cycle Assessment (S-LCA)", 2013.

[20] T.U. Daim, A. Udbye, A. Balasubramanian, "Use of analytic hierarchy process (AHP) for selection of 3PL providers", Journal of Manufacturing Technology Management, vol. 24, no. 1, pp. 28-51, 2012.

[21] C. Torres-Machi, A. Chamorro, E. Pellicer, V. Yepes, C. Videla, "Sustainable Pavement Management Integrating Economic, Technical, and Environmental Aspects in Decision Making", Transportation Research Record, vol. 2523, pp. 56-63, 2015.

[22] T.L. Saaty, The Analytic Hierarchy Process. McGraw-Hill, New York, 1980. 